\title{
LACTIC ACID PRODUCTION IN ELECTRODIALYSIS CULTURE
}

\author{
PEI-XIN YAO ${ }^{\dagger}$ AND KIYOSHI TODA* \\ Institute of Applied Microbiology, University of Tokyo, \\ Yayoi 1-1-1, Bunkyo-ku, Tokyo 113, Japan
}

(Received January 30, 1990)

\begin{abstract}
The rate of lactic acid production by Lactobacillus delbrueckii strain YPX was greatly improved by converting the acid to $\mathrm{Na}$-lactate and continuously removing the salt from the fermentation broth with an electrodialyzer. The fermentation using glucose $\left(85 \mathrm{~g} l^{-1}\right)$ as a raw material was completed in $9.9 \mathrm{~h}$ and the lactic acid concentration in the permeate compartment reached $90 \mathrm{~g} l^{-1}$. The average production rate was $8.7 \mathrm{~g} l^{-1} \mathrm{~h}^{-1}$, which was 12 times higher than that of the fermentation with direct electrodialysis of the lactic acid produced. The phosphate ions in the culture broth were electrodialyzed simultaneously with the lactate ions which caused a decrease in the fermentation rate in some cases.
\end{abstract}

Lactic acid fermentation is one of the most important microbial processes in the food industry and extensive studies have been made of the lactic acid producing bacteria and the fermentation processes (3). In lactic acid fermentation, the lactic acid produced inhibits further production of lactic acid $(4,6-8)$. The lactic acid cannot be separated from the culture broth by simple operations such as distillation, precipitation or extraction. Much of the cost of lactic acid production has been associated with the recovery and purification processes (17). In industrial lactic acid production, fermentation in the presence of excess calcium carbonate is used to prevent lowering of the $\mathrm{pH}$ of the broth (3). In this procedure the calcium carbonate reacts with the lactic acid to produce calcium lactate; thus the $\mathrm{pH}$ of the fermentation broth is maintained at about 5.0. However this method needs an additional process using sulfuric acid to convert calcium lactate to lactic acid(3). Hongo and Nomura $(5,11,12)$ reported the use of electrodialysis to lactic acid fermentation to alleviate the inhibition caused by the lactic acid produced. If the lactic acid is neutralized to Na-lactate, the inhibitory effect is decreased and the rate of

* Address reprint requests to: Dr. Kiyoshi Toda, Institute of Applied Microbiology, University of Tokyo, Yayoi 1-1-1, Bunkyo-ku, Tokyo 113, Japan.

$\dagger$ On leave from Shaanxi Institute of Microbiology, Xi'an, China. 
electrodialysis is better than with the acid-form lactic acid. Moreover if the culture broth is filtered through a hollow fiber membrane before circulating through the electrodialyzer, the attachment of the microbial cells on the anion exchange membrane and the cathode is avoided. Taniguchi and Kobayashi applied a ceramic filter and a hollow fiber membrane filter to concentrate lactic acid bacteria in the cultivation $(18,19)$. Boyaval and Raucourt reported lactic acid fermentation with cell separation by ultrafiltration and product recovery by electrodialysis $(2,15,16)$. However the final product was sodium lactate not lactic acid.

In the present study we used a hollow fiber membrane filter to avoid adherence of the bacterial cells to the anion exchange membrane and the cathode; electrodialysis was applied after converting lactic acid to sodium salt to alleviate the inhibitory effect of lactic acid on the fermentation and to increase the electrodialysis rate of the lactate ions.

\section{MATERIALS AND METHODS}

Bacterial strain. Lactobacillus delbrueckii strain YPX from laboratory stock was used throughout the present experiment. The stock culture was transferred to a new agar medium every week. This strain converted glucose to D-lactic acid by homolactic acid fermentation.

Medium. Four kinds of medium were used. The agar medium for the stock culture and for the viable cell count contained (grams per liter of tap water): glucose 10, yeast extract (Difco, Detroit) 5, polypeptone (Nihon Seiyaku Co., Tokyo) 10, $\mathrm{KH}_{2} \mathrm{PO}_{4} 2.5$, sodium thioglycolate 1 and agar 15 (pH 7.0). For the stock culture $20 \mathrm{~g} \mathrm{CaCO}_{3}$ was added to the medium. Medium $\mathrm{R}$ for refreshment culture contained (grams per liter of tap water): glucose 10 , yeast extract 25 , polypeptone 50 and $\mathrm{CaCO}_{3} 15$ ( $\mathrm{pH} 7.0$ ). Medium $\mathrm{S}$ for the seed culture contained (grams per liter of tap water): glucose 10 , yeast extract 5 , polypeptone 10 , sodium acetate 10 and $\mathrm{CaCO}_{3} 8$ ( $\mathrm{pH}$ 6.8). Medium $\mathrm{P}$ for lactic acid production contained (grams per liter of tap water): glucose 100 or 150 , yeast extract 20 , polypeptone $8, \mathrm{KH}_{2} \mathrm{PO}_{4} 2$, $\mathrm{MgSO}_{4} \cdot 7 \mathrm{H}_{2} \mathrm{O} 0.5$ and $\mathrm{NaCl} 0.1$ (initial $\mathrm{pH} 5.7-6.0$ ). If necessary $10 \%$ (wt/vol) $\mathrm{CaCO}_{3}$ was added to the medium $\mathrm{P}$ after being sterilized at $160^{\circ} \mathrm{C}$ for more than $2 \mathrm{~h}$.

Culture. A needle of the stab culture of Lactobacillus delbrueckii strain YPX was inoculated into $10 \mathrm{ml}$ of the medium $\mathrm{R}$ in a $20 \mathrm{ml}$ test tube. The preculture was obtained by incubating the test tube in static condition at $48^{\circ} \mathrm{C}$ for $24 \mathrm{~h}$. The seed culture was prepared by inoculating $10 \mathrm{ml}$ of the preculture into $90 \mathrm{ml}$ of the medium $\mathrm{S}$ in a $200 \mathrm{ml}$ conical flask and incubating at $48^{\circ} \mathrm{C}$ for $12 \mathrm{~h}$. In the main culture for lactic acid production, the medium $\mathrm{P}$ in a jar fermentor was inoculated with the seed culture at an inoculation ratio of $10 \%(\mathrm{vol} / \mathrm{vol})$ and incubated at $48^{\circ} \mathrm{C}$ for an appropriate time with gentle stirring $(54 \mathrm{rpm})$.

Apparatus for lactic acid fermentation with electrodialysis. Experimental setup of the bioreactor for lactic acid fermentation is shown in Fig. 1. The main parts of the bioreactor consisted of a $1.5-l$ jar fermentor (initial working volume was $1.1 l$; 


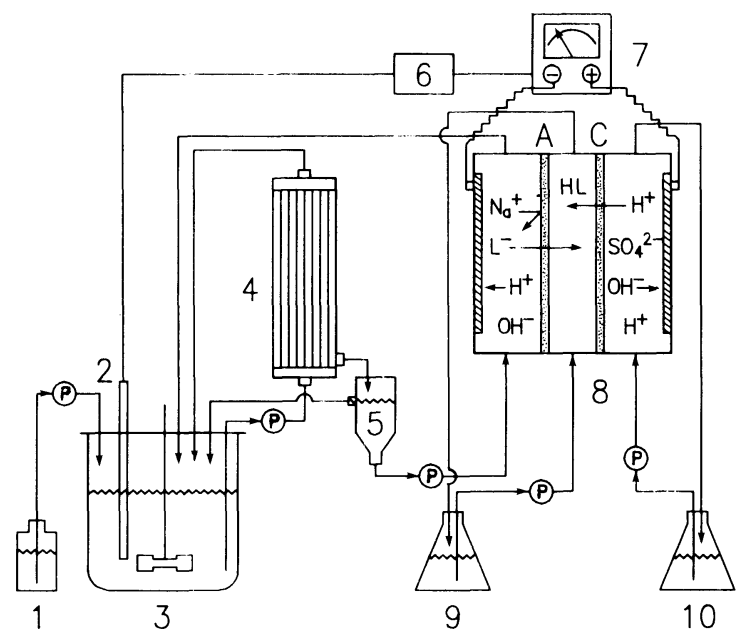

Fig. 1. Schematic diagram of a fermentation system with a membrane filtration module and an electrodialyzer. 1: $10 \mathrm{~N} \mathrm{NaOH}$ solution, 2: $\mathrm{pH}$ probe, 3: fermentor, 4: filter module, 5: filtrate receiver, 6: controller, 7: DC power supply, 8: electrodialysis module, 9: permeate solution, 10: $0.1 \mathrm{~N} \mathrm{H}_{2} \mathrm{SO}_{4}$ solution, p: liquid pumps.

Biostat MC, B. Brown, Melsungen AG, West Germany), a hollow fiber membrane filter module (Microza PSP-103, Asahi Kasei Co., Kawasaki, Japan) and an electrodialysis module (a modified model of Acid Dialyzer G1100, Asahi Kasei Co.). The filtration module contained 400 hollow fibers $(0.4 \mathrm{~mm}$ i.d., nominal pore size $0.2 \mu \mathrm{m}$ and effective filtration area $0.2 \mathrm{~m}^{2}$ ). Before use the filter module was sterilized by circulating $300 \mathrm{ppm}$ sodium hypochlorite solution ( $\mathrm{pH}$ adjusted to 12 with $\mathrm{NaOH}$ ) for $1 \mathrm{~h}$, washed with tap water until the effluent $\mathrm{pH}$ became 7-8, sterilized by circulating $50 \%$ ( $\mathrm{vol} / \mathrm{vol})$ ethanol solution for $1 \mathrm{~h}$ and finally washed with sufficient $(2,000 \mathrm{ml})$ heat-sterilized hot water $\left(60-80^{\circ} \mathrm{C}\right)$.

The electrodialysis module was internally separated into three compartments: cathode compartment, permeate compartment and anode compartment, by an anion-exchange membrane (type A-201) and a cation-exchange membrane (type K-201). The cathode was made of stainless stell (SUS316L) and the anode was platinum-coated titanium. The schematic diagram of the module is shown in Fig. 2. The fermented broth was circulated through the filtration module at a rate of $600 \mathrm{ml} \mathrm{min}^{-1}$. The filtrate passed through the cathode compartment at a flow rate of $80-120 \mathrm{ml} \mathrm{min}^{-1}$ and recycled back to the fermentor. The negatively charged lactate ions in the cathode compartment permeated through the anion exchange membrane but did not move across the cation exchange membrane. Therefore lactate ions accumulated in the permeate compartment where $500 \mathrm{ml}$ of distilled water was circulated at a flow rate higher than $100 \mathrm{ml} \mathrm{min}^{-1}$. The hydrogen ions remaining in the cathode compartment was attracted to the cathode and converted to hydrogen gas by accepting electrons from the electrode: 


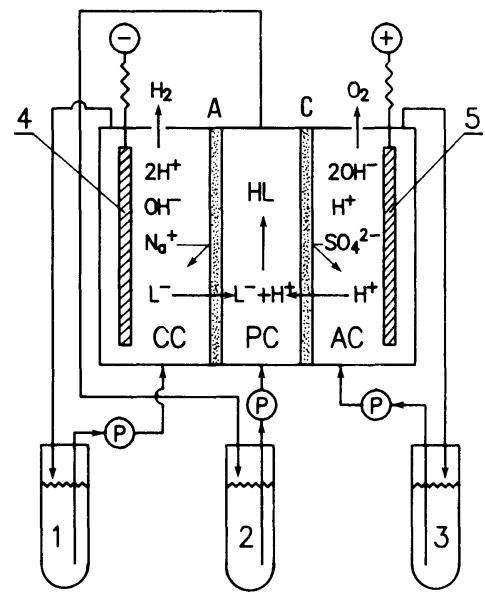

Fig. 2. Schematic diagram of electrodialyzer. 1: fermented broth, 2: permeate solution of lactic acid, 3: $0.1 \mathrm{~N} \mathrm{H}_{2} \mathrm{SO}_{4}$ solution, 4: cathode, 5: anode, P: liquid pump, A: anion-exchange membrane, $\mathrm{C}$ : cation-exchange membrane, $\mathrm{CC}$ : cathode compartment, PC: permeate compartment, AC: anode compartment.

$$
2 \mathrm{H}^{+}+2 \mathrm{e}^{-} \rightarrow \mathrm{H}_{2} \uparrow .
$$

The loss of hydrogen ions in turn increased the hydroxide ions by dissociation of water and changed the culture $\mathrm{pH}$ to the alkali side. When the sodium lactate was electrodialyzed, the rate was significantly increased due to the dissociation constant which was much higher than that of free lactic acid. The sodium ions remained in the cathode compartment and the hydroxide ions were returned to the fermentor where they combined with lactic acid to regenerate sodium lactate and to prevent the culture $\mathrm{pH}$ from becoming unfavorably acidic. A solution of sulfuric acid $(0.1 \mathrm{~N}$, $500 \mathrm{ml}$ initially) was circulated through the anode compartment. The hydrogen ions of the solution penetrated the cation exchange membrane to the permeate compartment driven by the electrodialysis but they did not diffuse out through the anion exchange membrane. The lactate and hydrogen ions transferred to the permeate compartment were combined to produce lactic acid;

$$
\mathrm{L}^{-}+\mathrm{H}^{+} \rightarrow \mathrm{HL} \text {. }
$$

The hydroxide ions of the water were attracted to the anode and converted to oxygen gas and hydrogen ions after giving electrons to the electrode:

$$
2 \mathrm{OH}^{+}-2 \mathrm{e}^{-}=\mathrm{O}_{2} \uparrow+2 \mathrm{H}^{+} .
$$

The hydrogen ions in the anode compartment were supplied from the above reaction. Therefore the concentrations of sodium hydroxide and sulfuric acid in each compartment for the cathode and anode did not change practically. There was no need to supplement them anew. Meanwhile lactic acid accumulated in the permeate 
compartment until the end of lactic acid fermentation.

The ion exchange membranes were supplied by Asahi Kasei Co., Kawasaki, Japan. The membranes have an available area of $150 \mathrm{~cm}^{2}$ and block ions of molecular size larger than 300 . The electrodialysis was conducted under an applied voltage of $11-17 \mathrm{~V}$ between a cathode of stainless steel plate (available area $175 \mathrm{~cm}^{2}$ ) and an anode of titan plate coated with platinum of the same area. The electric current of the dialysis ranged from 0 to $7 \mathrm{~A}$. In one experiment another electrodialysis module of smaller membrane size $\left(10 \mathrm{~cm}^{2}\right)$ was used.

Analyses. The lactic acid concentration was determined by the method of Barker and Summerson(1). The calcium lactate concentration was measured by the EDTA method (9). The glucose concentration was determined by the Glucostat method. The optical density of the culture broth was estimated at $660 \mathrm{~nm}$ after diluting with distilled water or $1 \mathrm{~N} \mathrm{HCl}$ (for Ca-lactate production). Viable cells were counted on agar medium plates incubated at $48^{\circ} \mathrm{C}$ in an anaerobic jar. The inorganic phosphate concentration was determined by the molybdenum method (10). The dry cell weight was measured by drying the washed wet cells at $105^{\circ} \mathrm{C}$ for more than $3 \mathrm{~h}$ to reach a constant weight.

\section{RESULTS AND DISCUSSION}

\section{Inhibition of lactic acid fermentation by three forms of lactates}

To investigate the inhibitory effects of lactic acid, sodium lactate and calcium lactate on the specific rate of lactic acid production, three runs of lactic acid fermentation were conducted under the following respective conditions: without $\mathrm{pH}$ control, at $\mathrm{pH} 5.5$ controlled with $10 \mathrm{~N} \mathrm{NaOH}$, and with an excess of $\mathrm{CaCO}_{3}$. Figure 3 shows the correlation between the specific rate of lactic acid production and the product concentration. The inhibition by free lactic acid was the strongest among them. The culture $\mathrm{pH}$ decreased from 5.5 to 3.7 with the increase of lactic acid concentration. The inhibition by Ca-lactate was the weakest; the bacteria

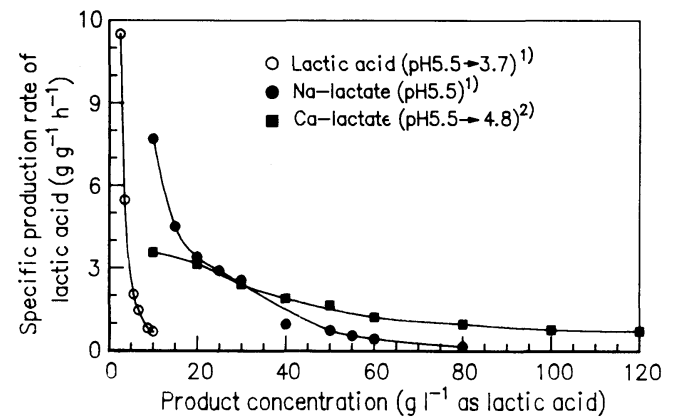

Fig. 3. Inhibition of lactic acid production by lactic acid, Na-lactate and Ca-lactate.

The concentration of the lactates are converted to that of lactic acid and expressed as lactic acid equivalent per culture volume (g-HL $\left.l^{-1}\right)$. 1) Glucose concentration in the medium was $100 \mathrm{~g} l^{-1}$. 2) Glucose concentration in the medium was $150 \mathrm{~g} l^{-1}$. 
produced lactic acid at a concentration of $1.3 \mathrm{M}\left(120 \mathrm{~g} l^{-1}\right.$ as lactic acid equivalent $)$ even though the $\mathrm{pH}$ dropped from 5.3 to 4.8 . The Na-lactate inhibited somewhat more than the Ca-lactate at concentrations higher than $30 \mathrm{~g} l^{-1}$; but the inhibition was less at the product concentration range of 10 to $20 \mathrm{gl} l^{-1}$. The degree of product inhibition was approximately in the following order; lactic acid $\gg \mathrm{Na}$-lactate $>\mathrm{Ca}$ lactate.

\section{Electrodialysis rates of two forms of lactates}

The solutions of Na-lactate at various concentrations and a Ca-lactate solution were circulated through the cathode compartment in the electrodialyzer of smaller size. The electrodialysis was done under the conditions: dialysis area, $10 \mathrm{~cm}^{2}$; applied voltage, $4 \mathrm{~V}$; electrodialysis current, maximum $0.16 \mathrm{~A}$. The amount of the lactate ions that permeated the anion exchange membrane was determined and is shown in Fig. 4. The electrodialysis rate of the lactate ions increased with increased concentration of Na-lactate. The electrodialysis rate of Ca-lactate was about half as much as that of Nalactate at the same normality. Besides, when Ca-lactate solution was used, a white colloidal substance precipitated on the surfaces of both the cathode and anion exchange membrane, which apparently decreased the rate of the electrodialysis. Therefore it was recommended that in practice lactic acid in the fermentation broth be changed to sodium salt rather than calcium salt to avoid the problem.

\section{Optimum pH for lactic acid fermentation}

To find the optimum $\mathrm{pH}$ for fermentation, a series of lactic acid fermentation trials were performed with the cultures maintained at $\mathrm{pH} 4.5$ to 6.5 with $10 \mathrm{~N} \mathrm{NaOH}$. The time courses of the glucose consumption and the lactic acid production in the cultures are shown in Fig. 5. The result of lactic acid fermentation without $\mathrm{pH}$

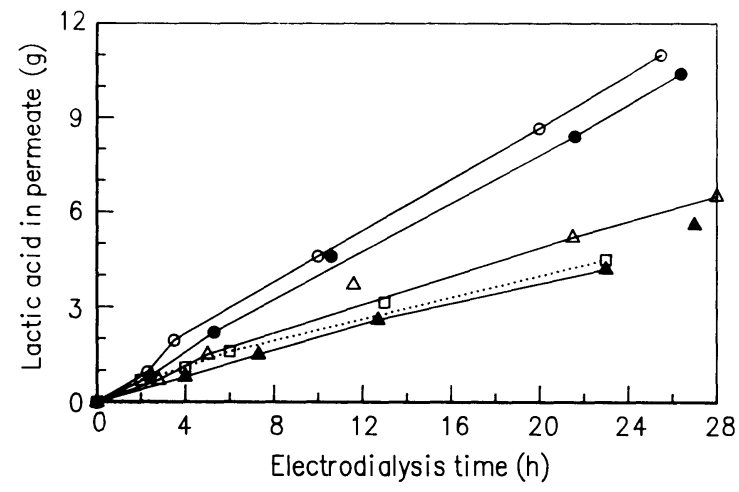

Fig. 4. Electrodialysis rate of lactates.

Concentration and species of lactates were: $0,0.89 \mathrm{~N} \mathrm{Na-lactate;} \bullet, 0.56 \mathrm{~N}$ Na-lactate; $\triangle, 0.22 \mathrm{~N}$ Na-lactate; $\Delta, 0.11 \mathrm{~N} \mathrm{Na-lactate} ; \square, 0.89 \mathrm{~N}$ Ca-lactate. Solid and dotted lines indicate $\mathrm{Na}$-lactate and $\mathrm{Ca}-$ lactate, respectively. 


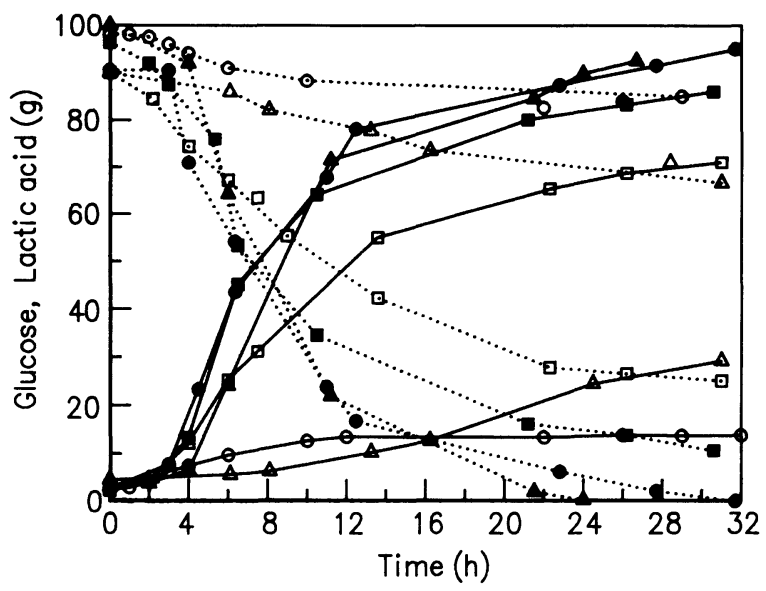

Fig. 5. Effect of $\mathrm{pH}$ on lactic acid fermentation. Culture $\mathrm{pH}$ was controlled at: $\boldsymbol{\square}$, $6.5 ; \triangle, 6.0 ; \bullet, 5.5 ; \square, 5.0 ; \triangle, 4.5 ;^{\circ} \circ$, uncontrolled ( $\mathrm{pH}$ changed from 5.5 to 3.7). Solid and dotted lines indicate lactic acid and glucose, respectively.

control, where $\mathrm{pH}$ of culture broth changed from 5.5 to 3.7 , is also shown for reference in Fig. 5.

The amount of lactic acid produced after $30 \mathrm{~h}$ was $28,72,92,93$ and $85 \mathrm{~g}$ respectively at $\mathrm{pH} 4.5,5.0,5.5$. 6.0 and 6.5. When $\mathrm{pH}$ was not controlled the lactic acid production was only $13 \mathrm{~g}$. So the optimum $\mathrm{pH}$ for the lactic acid production by Lactobacillus delbrueckii was 5.5-6.0. Also, the maximum lactic acid production rate $\left(10.8 \mathrm{~g} \mathrm{~h}^{-1}\right.$ at $4 \mathrm{~h}$ after the start of the fermentation) was attained at $\mathrm{pH} 5.5$. So in the later experiments the $\mathrm{pH}$ of the culture was maintained at around 5.5.

\section{Lactic acid fermentation without electrodialysis}

(1) $\mathrm{pH}$ of the culture not controlled. Before investigating effect of the product removal by electrodialysis on lactic acid fermentation, the variations in some cultural parameters during the course of a batch culture without the electrodialysis was traced and is shown in Fig. 6. The culture $\mathrm{pH}$ decreased from the initial value of 5.5 to 3.7 after $16 \mathrm{~h}$ of the fermentation and the production of lactic acid stopped at the lactic acid concentration of $12.5 \mathrm{~g} l^{-1}$ even though a large amount of glucose $\left(75 \mathrm{gl}^{-1}\right)$ and viable cells $\left(10^{7}-10^{8} \mathrm{ml}^{-1}\right)$ remained in the culture. The average productivity was estimated as $1.0 \mathrm{~g}$-lactic acid $l^{-1} \mathrm{~h}^{-1}$. The increase of OD after $16 \mathrm{~h}$ was not caused by the growth of cells (dry cell concentration remained constant) but by the precipitation of some components in the medium due to the lowering of $\mathrm{pH}$ to 3.7. The instantaneous production rate of lactic acid gave a maximum value of $2.0 \mathrm{~g} l^{-1} \mathrm{~h}^{-1}$ at $3 \mathrm{~h}$.

(2) $\mathrm{pH}$ of the culture controlled at 5.5 with $\mathrm{NaOH}$. Figure 7 shows the time course of the lactic acid fermentation in a batch culture when $\mathrm{pH}$ was controlled at 5.5 by adding $10 \mathrm{~N} \mathrm{NaOH}$. At $4-6 \mathrm{~h}$ of the fermentation, the lactic acid produc- 


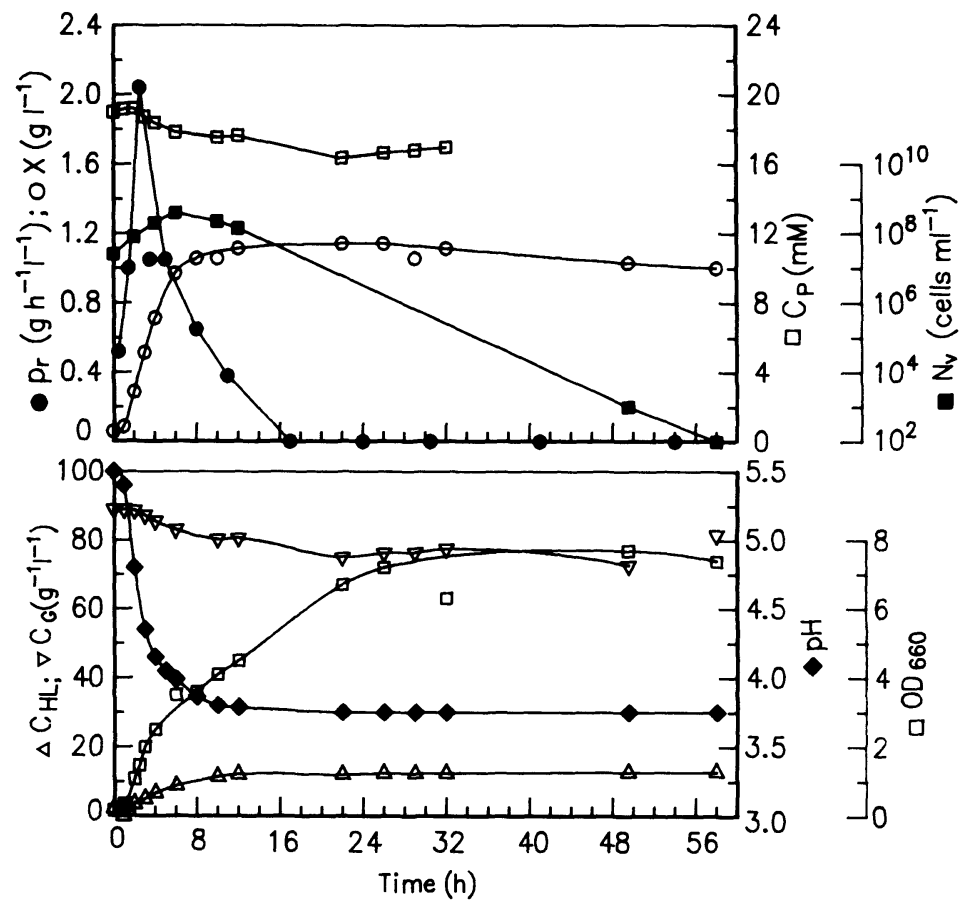

Fig. 6. Lactic acid fermentation without $\mathrm{pH}$ control.

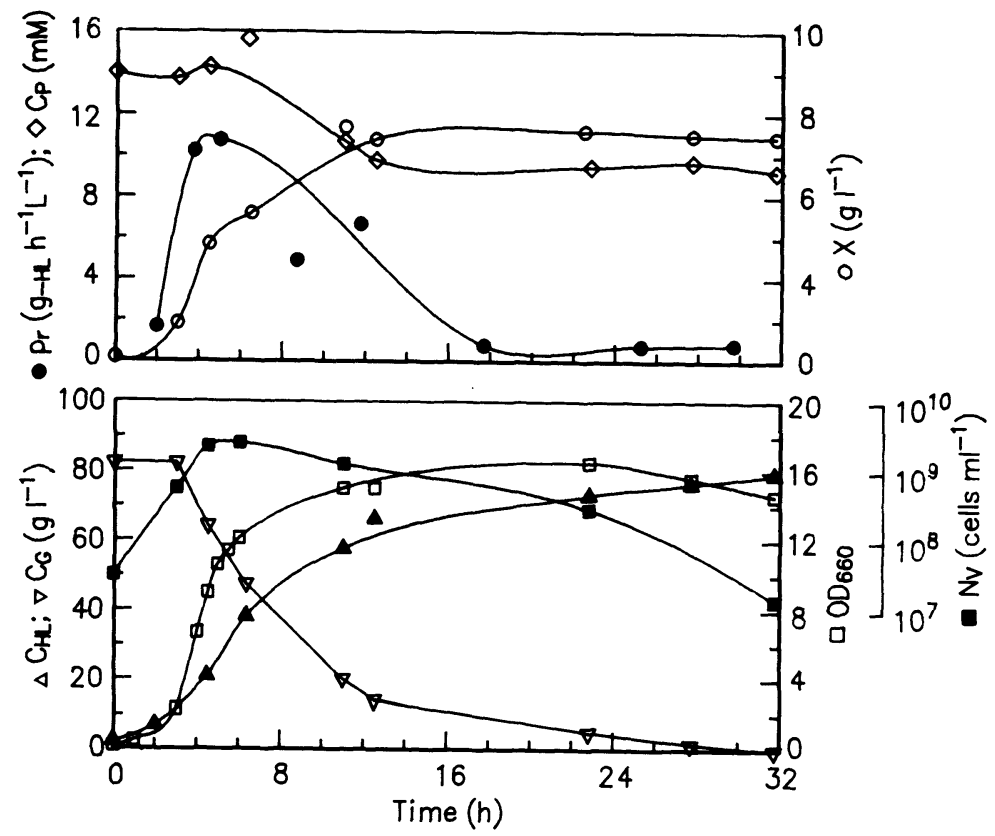

Fig. 7. Lactic acid fermentation with $\mathrm{pH}$ control $(\mathrm{pH}=5.5)$. 
tivity became $10 \mathrm{gl}^{-1} \mathrm{~h}^{-1}$ and the concentration of Na-lactate was $20-35 \mathrm{~g}$-lactic acid equivalent $l^{-1}$. However the productivity decreased with the increase of Na-lactate concentration higher than $40 \mathrm{~g}$-lactic acid equivalent $l^{-1}$. The fermentation stopped at $30 \mathrm{~h}$ after the glucose in the broth was completely depleted and the lactic acid concentration was $80 \mathrm{~g} l^{-1}$. The maximum and average productivities of lactic acid were 10.8 and $2.7 \mathrm{~g}$-lactic acid equivalent $l^{-1} \mathrm{~h}^{-1}$. The maximum productivity was five times more than in the fermentation without the $\mathrm{pH}$ control. In the following experiment we maintained the high peak productivity throughout a batch run of lactic acid fermentation by keeping the $\mathrm{pH}$ at 5.5 and electrodialyzing the lactic acid.

\section{Lactic acid fermentation with electrodialysis}

(1) Lactic acid in fermentation broth electrodialyzed directly. Figure 8 shows the time course of lactic acid fermentation with electrodialysis to determine the effect of low lactic acid concentration $\left(7 \mathrm{gl}^{-1}\right)$ on its production. The fermentation continued for $64 \mathrm{~h}$; without electrodialysis it had stopped at 16h (Fig. 6).
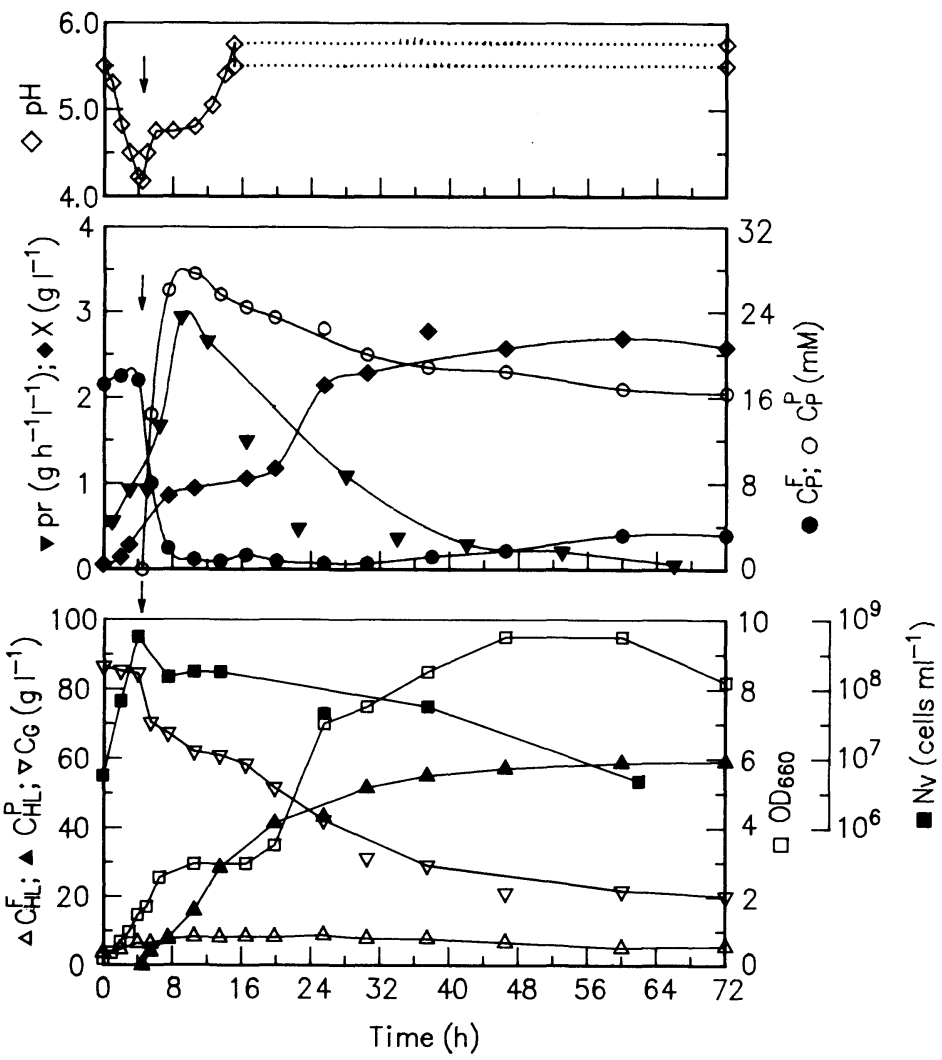

Fig. 8. Lactic acid fermentation with electrodialysis. Arrows indicate the time at which electrodialysis was started. The dotted lines indicate the range of $\mathrm{pH}$ control. 
And $20 \mathrm{~g} l^{-1}$ glucose remained in the culture after $64 \mathrm{~h}$. The maximum and average productivities of lactic acid were 2.9 and $0.72 \mathrm{gl}^{-1} \mathrm{~h}^{-1}$.

It may seem plausible to ascribe the deterioration of the fermentation rate to a continuing inhibition of the lactic acid remaining at a concentration of $7 \mathrm{~g} l^{-1}$ (see Fig. 3). But this was not the case. The result in Fig. 3 was obtained in a fermentation without electrodialysis and accordingly at a $\mathrm{pH}$ much lower than 5.5, while the result shown in Fig. 8 was mostly obtained at pH 5.5 (after $15 \mathrm{~h}$ ). The concentration of undissociated lactic acid, which inhibits the bacteria, was different in these two cases as will be explained later. Rather the loss of the electrolytes, such as sulfate, phosphate and some amino acids, due to the electrodialysis had an unfavorable effect on the viability and fermentation activity of the lactic acid bacteria and after $10 \mathrm{~h}$ this led to the significant decrease in the instantaneous productivity of lactic acid. The concentration of inorganic phosphate in the culture was decreased by the electrodialysis to one-tenth of the initial value. In view of the decrease of the inorganic phosphate concentration in the permeate solution after $10 \mathrm{~h}$ of the fermentation, perhaps the inorganic phosphate ions necessary for the bacterial growth in the culture could be supplemented from the permeate solution by passive diffusion through the anion exchange membrane.

(2) Lactic acid electrodialyzed after converting to $\mathrm{Na}$ salt. When the lactic acid produced in the fermentation broth was converted to $\mathrm{Na}$-lactate by adding $\mathrm{NaOH}$, a much higher dissociation constant of the lactate than the lactic acid increased the concentration of lactic acid ions in the cathode compartment and accelerated the rate of electrodialysis. Lactic acid fermentation was continued for $4.2 \mathrm{~h}$ with $\mathrm{pH}$ control ( $\mathrm{pH}$ 5.5) using $10 \mathrm{~N} \mathrm{NaOH}$ solution. Then the $\mathrm{NaOH}$ addition was stopped and the electrodialysis was started (Fig. 9). As expected, the rate of lactic acid production was improved owing to the less inhibitory effect of Na-lactate and the high electrodialysis rate of the lactic acid. The productivity of $10 \mathrm{~g} l^{-1} \mathrm{~h}^{-1}$ continued until the end of the fermentation. The time required for completing the fermentation was greatly shortened $(9.9 \mathrm{~h})$. The lactic acid concentration in the permeate solution was $90 \mathrm{~g}^{-1}$. The concentration of Na-lactate in the fermentor was maintained at about $30 \mathrm{~g}$-lactic acid equivalent $l^{-1}$. About $25 \%$ of the initial inorganic phosphate concentration ramained in the culture after $9.9 \mathrm{~h}$, as the time of electrodialysis was short $(5.7 \mathrm{~h})$. We attempted to maintain the optimum $\mathrm{pH}$ of the culture by the electrodialysis of the Na-lactate. However, $\mathrm{pH}$ of the culture could not be maintained at 5.5 because the production rate of lactic acid was somewhat faster than the electrodialysis rate: The culture $\mathrm{pH}$ was around 5.2. However, between $9.9 \mathrm{~h}$ and $13.3 \mathrm{~h}$ the culture $\mathrm{pH}$ could be maintained at 5.55.75 by the electrodialysis. After the time $(10.3 \mathrm{~h})$ when the glucose was depleted, glucose powder $(5 \mathrm{~g}$ each) was fed intermittently to the culture six times every 30 min. During the glucose-fed culture the fermentation continued further until a high lactic acid concentration in the permeate solution $\left(120 \mathrm{~g} l^{-1}\right.$ at $\left.14.3 \mathrm{~h}\right)$ was attained. This indicates the feasibility of continuous fermentation using the electrodialysis culture. The lactate ions remaining in the final fermentation broth 


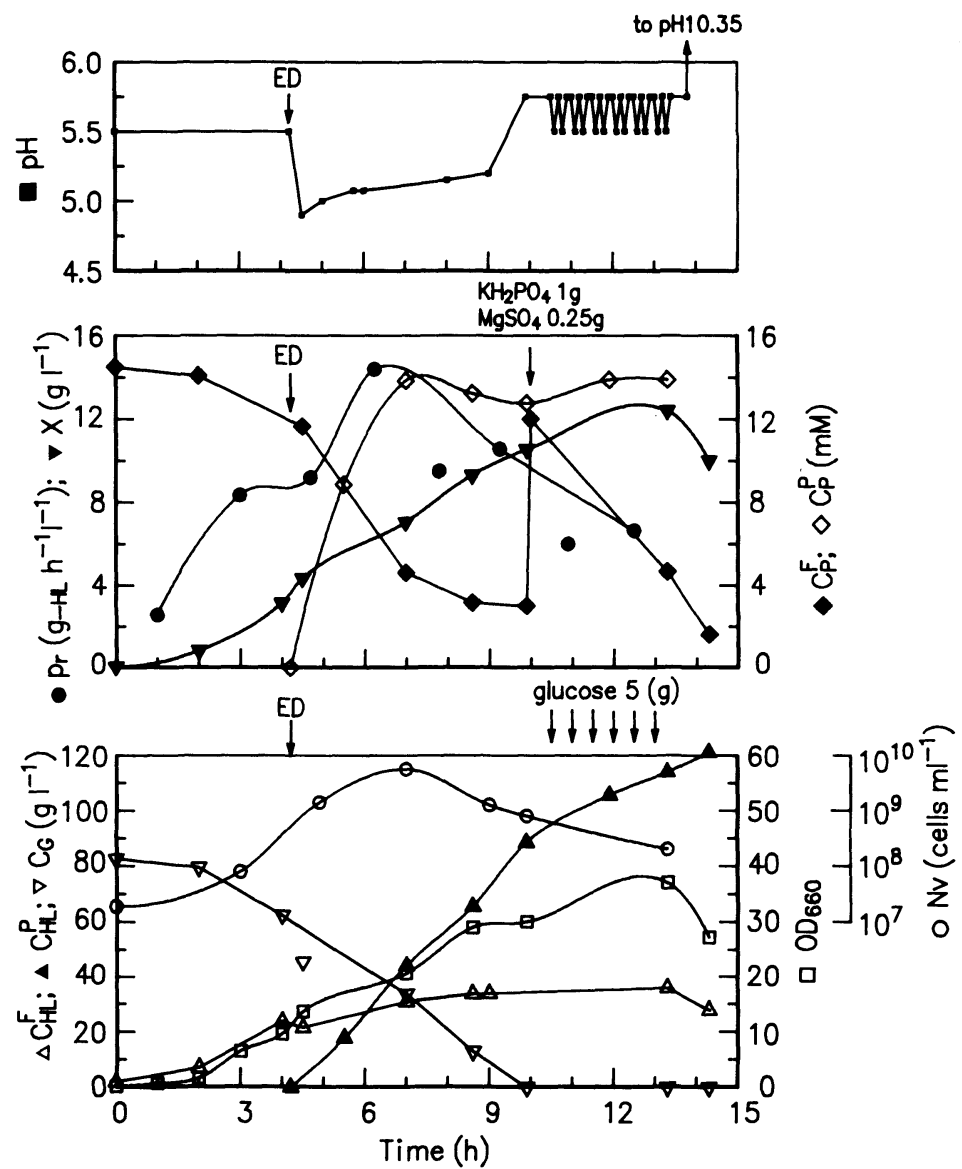

Fig. 9. Lactic acid fermentation with electrodialysis of sodium lactate.

The culture $\mathrm{pH}$ was maintained at 5.5 with the addition of $\mathrm{NaOH}$ solution until $4.2 \mathrm{~h}$. Arrows indicate the time of starting electrodialysis, addition of glucose and supplement of inorganic nutrients, respectively.

could be recovered more by releasing the upper limit of the $\mathrm{pH}$ control, as indicated by the decrease of lactic acid concentration in the fermentation broth while (13.8-14.3 h) the upper limit of $\mathrm{pH}$ control was changed from 5.75 to 10.35 .

\section{Comparison of the four procedures of lactic acid fermentation}

The maximum values of total and viable cell concentrations and instantaneous productivity are collected from the above four runs of lactic acid fermentation and are shown in Table 1 for comparison. These parametric quantities are largest for the culture with the $\mathrm{NaOH}$ added during the early phase of the culture and subsequent electrodialysis. The dry weight concentration, viable cell concentration, and lactic acid production rate were 3.9, 9.4, and 4.9 times more than in the 
Table 1. Comparison of lactic acid fermentation under different culture controls.

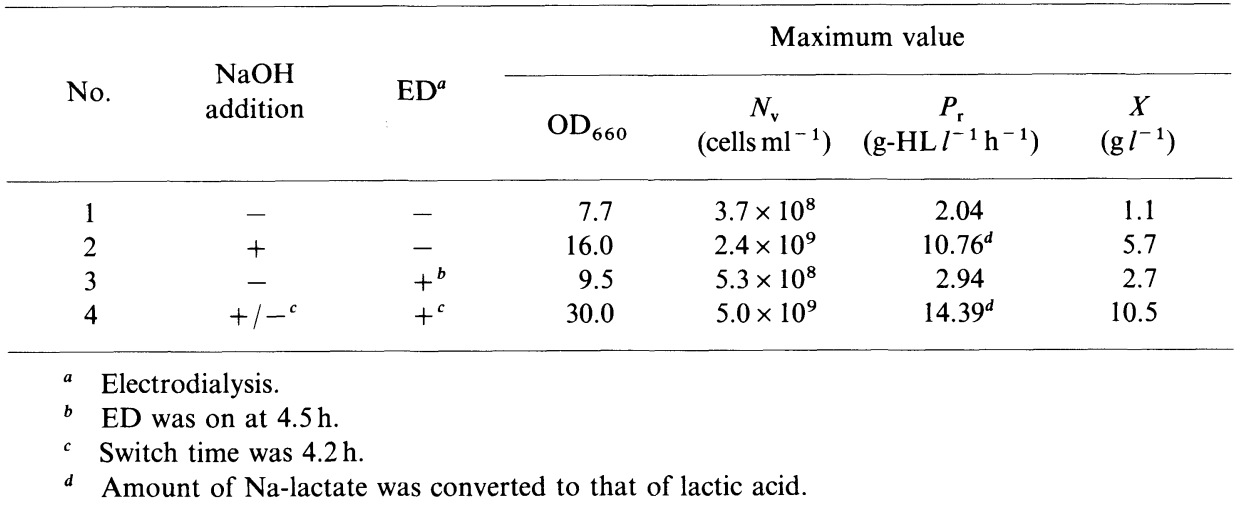

electrodialysis fermentation without the addition of $\mathrm{NaOH}$.

Table 2 shows the comparison of glucose consumption, average productivity and the amount and form of lactate permeated among the four fermentation procedures. The best results occurred when $\mathrm{NaOH}$ was added and electrodialysis was applied. The production of lactic acid was completed within $9.9 \mathrm{~h}$, while the other three fermentation processes took $32-72 \mathrm{~h}$. The average productivity of $8.7 \mathrm{~g} l^{-1} \mathrm{~h}^{-1}$ was 12 times that of the the electrodialysis-fermentation without the addition of $\mathrm{NaOH}$. The electrodialysis rate of lactic acid was estimated as $11.3 \mathrm{~g} \mathrm{~h}^{-1}$ which was 15 times faster than that of the reference fermentation. The sodium lactate concentration in the culture was maintained at $30-35 \mathrm{~g} l^{-1}(=0.33-0.39 \mathrm{M}$, Fig. 9) during the electrodialysis. The high concentration (4-5 fold that in Fig. 8) of sodium lactate was important for increasing the electrodialysis rate without deteriorating the fermentative activity of the bacteria.

The electrodialysis fermentation without the use of $\mathrm{NaOH}$ was performed mostly at $\mathrm{pH} 5.5$ and the lactic acid concentration of the culture was maintained around $7 \mathrm{~g} l^{-1}(=0.078 \mathrm{M}$, Fig. 8) during the electrodialysis. The lactic acid concentration was much higher than that $\left(3.2 \times 10^{-6} \mathrm{M}\right)$ in a solution of lactic acid at $\mathrm{pH} 5.5$, which was calculated using a $\mathrm{pK}$ value of 3.8. This indicates that most of the lactic acid in the culture must be in the form of salts. In parallel with the electrodialysis of lactic acid ions, some anions in the fermentation broth such as $\mathrm{H}_{2} \mathrm{PO}_{4}{ }^{-}$and $\mathrm{SO}_{4}{ }^{2-}$ were also lost from the culture during the electrodialysis. The remaining counter ions $\left(\mathrm{K}^{+}\right.$and $\left.\mathrm{Mg}^{2+}\right)$ and the basic amino acids such as lysine, arginine and histidine reacted with the lactic acid ions to generate the corresponding lactates. It is not known what kind(s) of lactate was predominant in the culture, but they must be more inhibitory to lactic acid production than sodium lactate because the maximum specific production rate at the early phase of the electrodialysis culture, where the inorganic salts were not yet depleted from the culture, was one-fifth (Table 1) that in a fermentation with electrodialysis of sodium lactate. The low average specific productivity (one-twelfth, Table 2 ) may be ascribed to the 


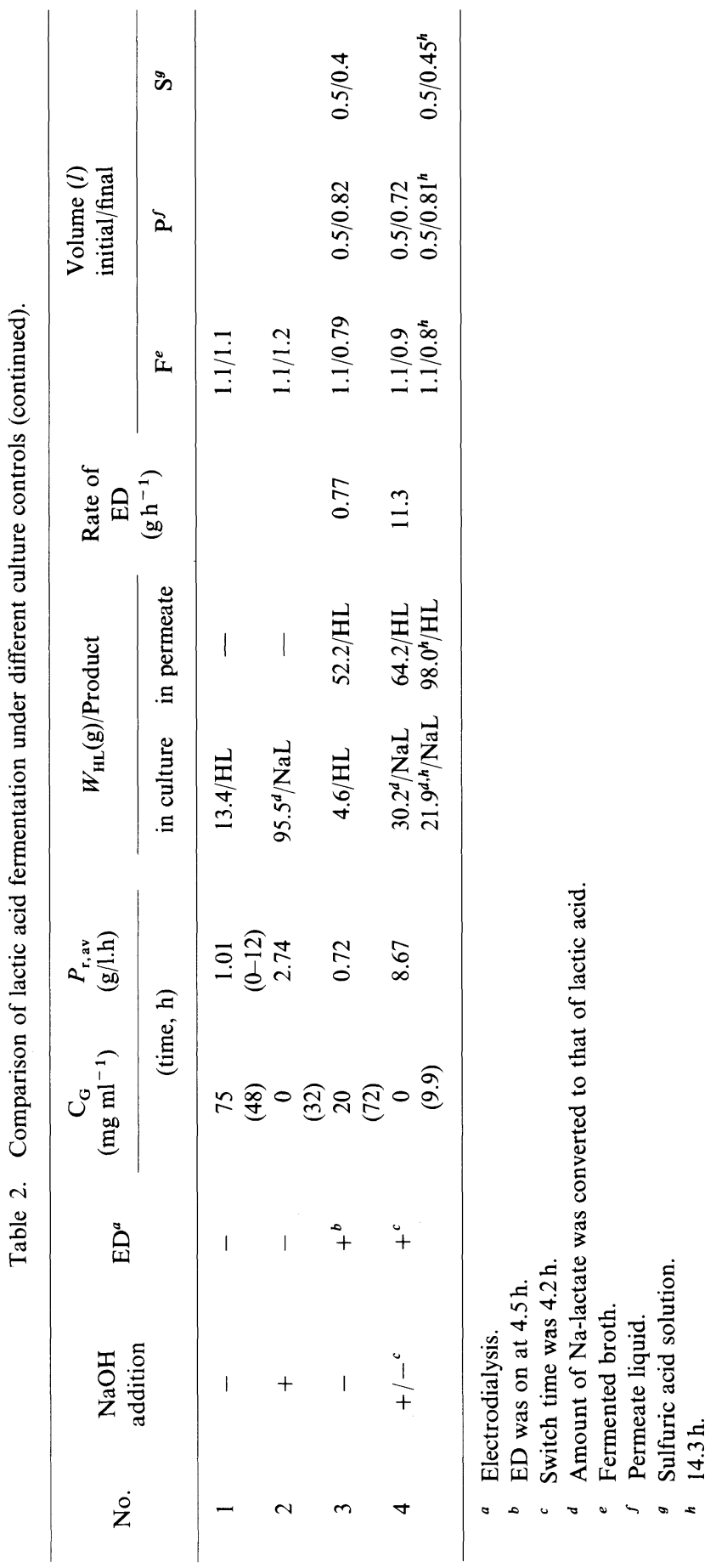


depletion of inorganic phosphate ions after $10 \mathrm{~h}$.

In addition to movement of the ions through the ion exchange membranes, fluid moved through the membranes by electroosmosis. Moreover a fraction of the water molecules were decomposed by electrolysis in the dialyzer. These caused the change in liquid volume of the culture in the fermentor, the permeate solution and the sulfuric acid solution. The last column in Table 2 shows the volume change. The rate of lactic acid fermentation was greatly accelerated by alleviating the product inhibition by converting lactic acid to Na-lactate and its separation through the ionexchange membranes in an electrodialyzer. The yields of lactic acid on consumed glucose were 0.955 and $0.964\left(\mathrm{~g} \mathrm{~g}^{-1}\right)$ for runs 2 and 4 in Table 2. However, the parametric values for runs 1 and 3 were 0.844 and 0.707 . The reason for the lower product yields in the latter experiments is left for further investigation.

In this study lactic acid was recovered simultaneously with the fermentation after converting the product to its salt. This principle can be applied to the microbial production of the other organic acids such as citric acid, acetic acid(13) and some amino acids (14). The reduction in viability of the microorganisms and the loss of ionic nutrients such as phosphate must be taken into account in industrial application of the novel fermentation technique. Studies to resolve these problems are in progress.

\section{NOMENCLATURE}

C concentration $\left(\mathrm{g} l^{-1}, \mathrm{~mm}\right)$

$\mathrm{CaL}_{2}$ calcium lactate

ED electrodialysis

HL lactic acid (or its equivalent)

$\mathrm{L}^{-}$lactate ion

$\mathrm{NaL}$ sodium lactate

$N_{\mathrm{V}}$ viable cell concentration (cells $\mathrm{ml}^{-1}$ )

$P_{\mathrm{r}}$ instantaneous productivity of lactic acid $\left(\mathrm{g} l^{-1} \mathrm{~h}^{-1}\right)$

$P_{\mathrm{r}, \mathrm{av}}$ average productivity of lactic acid $\left(\mathrm{g} l^{-1} \mathrm{~h}^{-1}\right)$

$W_{\mathrm{HL}}$ amount of lactic acid (g)

$X$ dry cell concentration $\left(\mathrm{g} l^{-1}\right)$

Suffix

G glucose

HL lactic acid (or equivalent)

P inorganic phosphate

Superscript

F fermentation broth

$P$ permeate

We are greatly indebted to Messrs. M. Hamada, H. Mitsuhara and T. Matsui of Asahi Chemical Ind. Co., Ltd. for the construction of the electrodialysis module. P-X Yao thanks Dr. 
H. Yoshizumi of Suntory Limited for his encouragement of this study.

\section{REFERENCES}

l) Barker, S. B. and Summerson, W. H., The colorimetric determination of lactic acid in biological materials, J. Biol. Chem., 138, 535-554 (1941).

2) Boyaval, P., Corre, C., and Terre, S., Continuous lactic acid fermentation with concentrated product recovery by ultrafiltration and electrodialysis. Biotechnol. Lett., 9, 207-212 (1987).

3) Buchta, K., Lactic acid. In Biotechnology, vol. 3, ed. by Dellweg, H., Verlag Chemie, Weinheim, Federal Republic of Germany (1983), p. 410-417.

4) Friedman, M. R. and Gaden, E. L. Jr., Growth and acid production by Lactobacillus delbrueckii in a dialysis culture system. Biotechnol. Bioeng., 12, 961-974 (1970).

5) Hongo, M., Nomura, Y., Iwahara, M., Novel method of lactic acid production by electrodialysis fermentation, Appl. Environ. Microbiol., 52, 314-319 (1986).

6) Ishizaki, A. and Ohta, T., Batch culture kinetics of L-lactate fermentation employing Streptococcus sp. IO-1, J. Ferment. Bioeng., 67, 46-51 (1989).

7) Keller, A. K. and Gerhardt, P., Continuous lactic acid fermentation of whey to produce a ruminant feed supplement high in crude protein. Biotechnol. Bioeng., 17, 997-1018 (1975).

8) Longsworth, L. G. and MacInnes, D. A., Bacterial growth with automatic $\mathrm{pH}$ control. J. Bacteriol., 29, 595-607 (1935).

9) Nihon Kagakukai, Kagakubinran Kisohen (Chemistry Handbook, Fundamentals) (in Japanese), Maruzen, Tokyo (1975), p. 1528-1551.

10) Nihon Kagakukai, Kagakubinran Kisohen (Chemistry Handbook, Fundamentals) (in Japanese), Maruzen, Tokyo (1975), p. 1540.

11) Nomura, Y., Iwahara, M., Hongo M., Lactic acid production by electrodialysis fermentation using immobilized growing cells. Biotechnol. Bioeng., 30, 788-793 (1987).

12) Nomura, Y., Iwahara, M., Nakamura, T., and Hongo, M., Tuuden touseki hakkouhou ni yoru nyuusan no seisan, daizu nijiru no yuukou riyou (Production of lactic acid by electrodialysis fermentation: Utilization of soy bean stock) (in Japanese), Nippon Nōgei Kagaku Kaishi, 62, 1757-1762 (1988).

13) Nomura, Y., Iwahara, M., Hongo M., Acetic acid production by an electrodialysis fermentation method with a computerized control system. Appl. Environ. Microbiol., 54, 137-142 (1988).

14) Nomura, Y., Iwahara, M., and Hongo, M., Tuuden touseki hakkouhou no L-rijin hakkou eno ouyou (Application of electrodialysis fermentation to L-lysine fermentation) (in Japanese), Nippon Nōgei Kagaku Kaishi, 61, 1293-1295 (1987).

15) Raucourt, A. de, Girard, D., Prigent, Y., and Boyaval, P., Lactose continuous fermentation with cells recycled by ultrafiltration and lactate separation by electrodialysis: modeling and simulation. Appl. Microbiol. Biotechnol., 30, 521-527 (1989).

16) Raucourt, A. de, Girard, D., Prigent, Y., and Boyaval, P., Lactose continuous fermentation with cells recycled by ultrafiltration and lactate separation by electrodialysis: model identification. Appl. Microbiol. Biotechnol., 30, 528-534 (1989).

17) Smith, B. R., MacBean, R. D., and Cox, G. C., Separation of lactic acid from lactose fermentation liquors by reverse osmosis. Austral. J. Dairy Technol., 32, $23-26$ (1977).

18) Taniguchi M., Kotani, N., Kobayashi, T., High-concentration cultivation of lactic acid bacteria in fermentor with cross flow filtration. J. Ferment. Technol., 65, 179-184 (1987).

19) Wang, E., Hatanaka, H., Iijima, S., Takebayashi, T., Shi, Z., Shimizu, K., Matsubara, M., and Kobayashi, T., Control of cell and lactate concentration in a hollow-fiber bioreactor for lactic acid fermentation. J. Chem. Eng. Jpn., 21, 36-40 (1988). 